\title{
Size Effect of Mechanical Properties of Coal Measures Sandstone under High Strain Rate
}

\author{
Guo Shiru ${ }^{1 *}$, Mao Xianbiao ${ }^{1,2}$, Li Ming ${ }^{2}$, Mao Rongrong ${ }^{1}$, Hu Shanchao ${ }^{1}$ \\ ${ }^{I}$ School of Mechanics and Civil Engineering, China University of Mining \& Technology, 221116Xuzhou, China. \\ ${ }^{2}$ State Key Laboratory for Geomechanics and Deep Underground Engineering, China University of Mining \& \\ Technology, 221116, Xuzhou, China.
}

*Corresponding Author: Guo Shiru, School of Mechanics and Civil Engineering, China University of Mining \& Technology, 221116Xuzhou, China.

\begin{abstract}
In the process of mining, the surrounding rock is in a complex environment with high strain rate in many cases, such as roadway blasting and Coal cutting operation of Shearer. The study of mechanical properties of rock under high strain rate is an important theoretical basis to ensure the effective control of mine surrounding rock stability and safe production. Five specimens with diameters of $50 \mathrm{~mm}$, aspect ratios of $0.3,0.5,0.7,0.8$, and 1.0 were selected to analyze the variation of stress-strain curves and mechanical parameters (dynamic modulus of elasticity, dynamic peak stress and dynamic peak strain) with aspect ratios of sandstone. The influence of specimen size on rock mechanical properties under high strain rates was obtained. The research results can provide important reference for failure law of coal measures sandstones under high strain rate environment and engineering stability analysis.
\end{abstract}

Keywords: coal series sandstone; high strain rate; size effect; mechanical property; SHPB

\section{INTRODUCTION}

Scale rate is one of the main factors affecting the mechanical properties of rock materials. There are great differences in mechanical properties of rock specimens of different sizes. The research on rock size effect can be traced back to the research work of $\mathrm{Griffth}^{[1]}$ in 1921. In this paper, the size effect is introduced into rock mechanics for the first time, and the discontinuity or gap of the material itself is eliminated by the size effect. Later Bunting studied the relationship between strength and aspect ratio of anthracite, and found that the compressive strength of anthracite decreases rapidly when the aspect ratio is greater than 1 , and the strength is almost unchanged when the aspect ratio is further increased. Hudson $\mathrm{J}$ a et $\mathrm{al}^{[2]}$. Studied the uniaxial compression tests of marble with different aspect ratios, and found that the relationship between the strength of marble and aspect ratio is very obvious. Bazant $\mathrm{Z}$ $\mathrm{P}^{[3]}$ through the research obtained the macroscopic size may coupled with other mechanical or physical characteristics into a unit dimension quantity. J C Jaeger et al. ${ }^{[4]}$ carried out a large number of experimental studies on rock, and obtained the relationship between the average strength and size of rock samples. The relationship between strength and size of rock samples was determined by Obert $\mathrm{L}^{[5]}$.Su Chengdong ${ }^{[6]}$ studied the influence of the size of marble sample on the impact tendency. It is concluded that the aspect ratio not only affects the bearing capacity of the rock, but also affects the deformation after the peak value of the sample. Du Jing ${ }^{[7]}$ studied the effect of different aspect ratios on rock impact compression at the same strain rate. It was found that the deformation modulus of rock increased with the increase of aspect ratio. Yin Xiaotao et al. ${ }^{[8]}$ used PFC software to simulate uniaxial compression test and triaxial compression test of rock specimens with aspect ratios of 0.5 , 1.0, 1.5, 2.0, 2.5, 3.0, 4.0, respectively. The effects of aspect ratio on failure process, failure mode, stress-strain curve and energy transfer during failure process were analyzed.

\section{BRIEF InTROdUCTION OF EXPERIMENTAL METHODS AND PRINCIPLES}

At present, the split Hopkinson Pressure Bar (SHPB) test system is widely used to study the mechanical properties of rock under high strain rate, and the data of rock dynamic properties are obtained. The SHPB test system device is shown in Figure 1. 
The SHPB test system is based on two basic assumptions: one-dimensional stress wave hypothesis and stress uniformity hypothesis. The one-dimensional stress wave hypothesis assumes that the stress wave propagates in one-dimensional direction between the incident bar, the specimen and the transmission bar. The stress homogeneity hypothesis assumes that the stress and strain at each point in the specimen are uniformly distributed when the stress wave acts on the specimen.

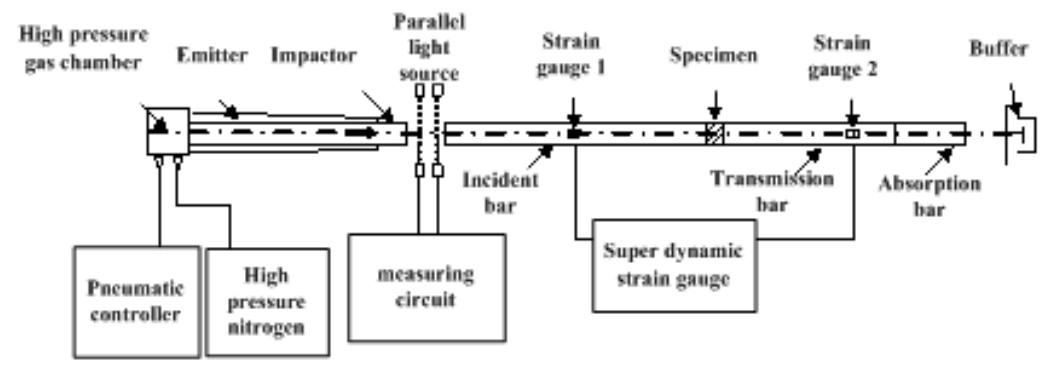

Figure1. The SHPB test system device

The one-dimensional stress wave analysis of an elastic bar shows that there is a linear relationship between stress and particle velocity and strain as long as the compression bar remains elastic during the test. The stress propagation process in the SHPB test is analyzed with the help of Figure 2.The force $P_{1}$ and particle velocity $v_{1}$ at the interface between the specimen and the end face of the incident bar can be obtained at $X_{1}$.

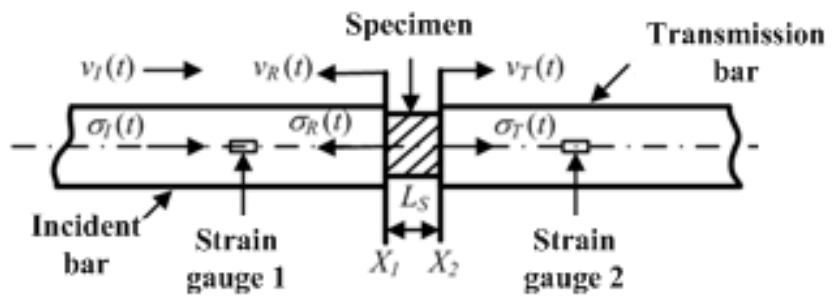

Figure2. SHPB stress pulse propagation diagram

$$
\begin{aligned}
& P_{l}=A_{0}\left[\sigma_{I}(t)+\sigma_{R}(t)\right]=E_{0} A_{0}\left[\varepsilon_{I}(t)+\varepsilon_{R}(t)\right] \\
& v_{l}=v_{I}(t)+v_{R}(t)=C_{0}\left[\varepsilon_{I}(t)-\varepsilon_{R}(t)\right]
\end{aligned}
$$

According to the above formula, the force $P_{2}$ and particle velocity $v_{2}$ at the interface $X_{2}$ between the specimen and the transmission rod are deduced as follows:

$$
\begin{aligned}
& P_{2}=A_{0} \sigma_{T}(t)=E_{0} A_{0} \varepsilon_{T}(t) \\
& v_{2}=v_{T}(t)=C_{0} \varepsilon_{T}(t)
\end{aligned}
$$

(4)The average stress $\sigma(t)$, strain rate $\dot{\varepsilon}(t)$ and strain $\varepsilon(t)$ of the specimen can be obtained from the forces $P_{1}, P_{2}$ and particle velocities $v_{1}$ and $v_{2}$ at the interfaces $X_{1}$ and $X_{2}$. According to the propagation law of stress wave, the stress wave will propagate back and forth between the interface $X_{1}$ and the interface $X_{2}$ in the test. Until the stress and strain along the length direction of the rock specimen tend to be uniform, the stress at both ends of the specimen can be equal, that is, satisfying $P_{1}=P_{2}$, the homogeneity assumption can be expressed as:

$$
\begin{aligned}
& \sigma_{I}(t)+\sigma_{R}(t)=\sigma_{T}(t) \\
& \varepsilon_{I}(t)+\varepsilon_{R}(t)=\varepsilon_{T}(t)
\end{aligned}
$$

Assuming that the strain of the bar is $\varepsilon(t)$, the overall displacement of the bar can be obtained as follows:

$$
u=C_{0} \int_{0}^{t} \varepsilon(t) d t
$$

When the stress wave acts on the incident bar, the overall displacement of the bar can be expressed as: 
$u_{1}=C_{0} \int_{0}^{t} \varepsilon_{I}(t) d t+\left(-C_{0} \int_{0}^{t} \varepsilon_{R}(t) d t\right)=C_{0} \int_{0}^{t}\left(\varepsilon_{I}(t)-\varepsilon_{R}(t)\right) d t$

Similarly, the displacement of the transmission rod is expressed as:

$u_{2}=C_{0} \int_{0}^{t} \varepsilon_{T}(t) d t$

In the formula, $C_{0}$ is the longitudinal wave velocity of the incident rod and the transmission rod, $\varepsilon_{I}(t) 、 \varepsilon_{R}(t)$ and $\varepsilon_{T}(t)$ the strain signal under the action of the incident stress wave, the reflected stress wave and the transmitted stress wave respectively. Therefore, the average strain in the sample is obtained.

$\varepsilon=\frac{u_{1}-u_{2}}{L_{S}}=\frac{C_{0}}{L_{S}} \int_{0}^{t}\left(\varepsilon_{I}(t)-\varepsilon_{R}(t)-\varepsilon_{T}(t)\right) d t$

The average strain rate in the sample is:

$\dot{\varepsilon}=\frac{C_{0}}{L_{S}}\left[\varepsilon_{I}(t)-\varepsilon_{R}(t)-\varepsilon_{T}(t)\right]$

In summary, the three wave processing formula for SHPB test data can be obtained:

$$
\begin{aligned}
& \dot{\varepsilon}=\frac{C_{0}}{L_{S}}\left[\varepsilon_{I}(t)-\varepsilon_{R}(t)-\varepsilon_{T}(t)\right] \\
& \varepsilon=\frac{C_{0}}{L_{S}} \int_{0}^{t}\left[\varepsilon_{I}(t)-\varepsilon_{R}(t)-\varepsilon_{T}(t)\right] d t \\
& \sigma=\frac{A_{0}}{2 A_{S}} E_{0}\left[\varepsilon_{I}(t)+\varepsilon_{R}(t)+\varepsilon_{T}(t)\right]
\end{aligned}
$$

In the formula, $E_{0} 、 A_{0}$ express as the elastic modulus of the bar material and the area of the compression bar, $L_{S} 、 A_{s}$ express as the original length and the cross-sectional area of the specimen respectively.

\section{EXPERIMENTAL RESULTS AND ANALYSIS}

In the study of size effect on mechanical properties of coal measures sandstone under high strain rate, the impact pressure of SHPB test system is set at $\mathrm{P}=0.29 \mathrm{MPa}$. In the test, five kinds of coal measures sandstone samples with diameter of $50 \mathrm{~mm}$, aspect ratio of $0.3,0.5,0.7,0.8$ and 1.0 are selected, as shown in Figure 3. Repeat 3-5 times at each air pressure level to ensure sufficient data for test results. The variation of stress-strain curves and mechanical parameters (dynamic elastic modulus, dynamic peak stress and dynamic peak strain) of sandstone with aspect ratio are analyzed. The influence of specimen size on rock mechanical properties under high strain rate is obtained.

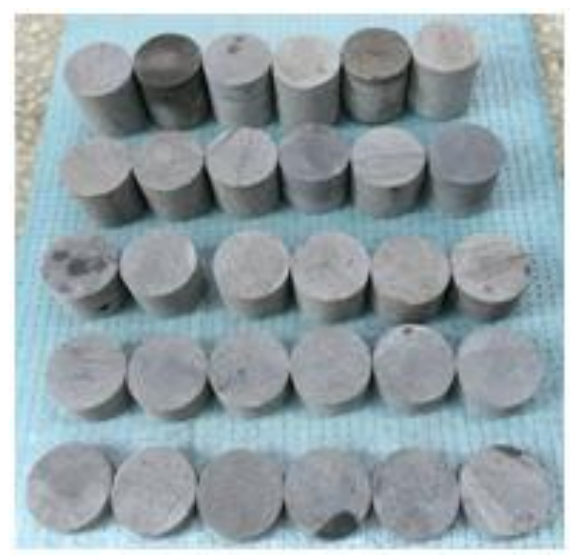

Figure3. The coal measures sandstone specimen 


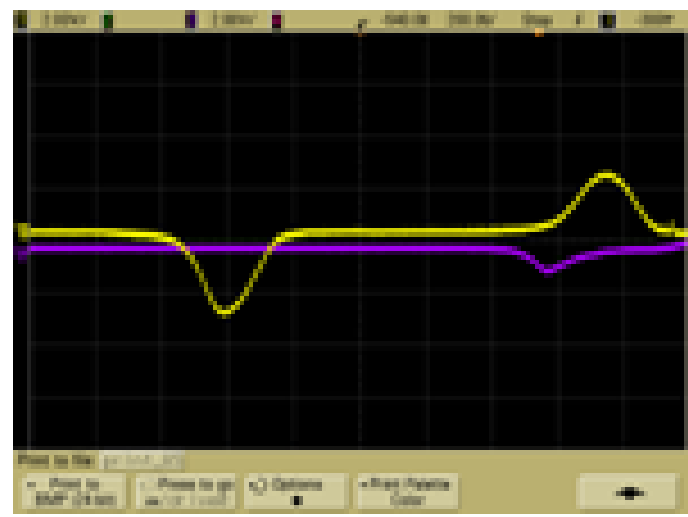

Figure4. The SHPB test waveform of coal measures sandstone

The transient waveform storage is used to obtain the waveform of the voltage signal in the SHPB test, as shown in Figure 4. The yellow line is the recording signal of the strain gauge on the incident bar, including the incident wave signal and the reflected wave signal. The purple line records the strain gauge on the transmission rod, and only includes the transmitted wave signal. There is no significant transverse vibration in the process of stress wave propagation, which satisfies the one-dimensional propagation hypothesis and stress homogeneity hypothesis. The stress, strain and strain rate of coal measures sandstone are obtained by separating incident wave, reflected wave and transmitted wave and calculating formula (12) of three wave method. Table 1 shows the impact velocities and strain rates of specimens with different aspect ratios under atmospheric pressure of $0.29 \mathrm{MPa}$.

Table1. Variation of strain rate with specimen size

\begin{tabular}{|c|c|c|c|c|c|c|c|c|}
\hline Number & $\beta$ & $V /\left(\mathrm{m} \cdot \mathrm{s}^{-1}\right)$ & $\bar{V} /\left(\mathrm{m} \cdot \mathrm{s}^{-1}\right)$ & $D / \mathrm{mm}$ & $\mathrm{L} / \mathrm{mm}$ & $M / g$ & $\dot{\varepsilon} / \mathrm{s}^{-1}$ & $\overline{\dot{\varepsilon}} / \mathrm{s}^{-1}$ \\
\hline $1-1$ & \multirow[t]{3}{*}{0.3} & 7.61 & \multirow[t]{3}{*}{7.51} & 49.2 & 16.1 & 80.58 & 186.75 & \multirow[t]{3}{*}{160.19} \\
\hline $1-2$ & & 7.37 & & 49.3 & 16.0 & 81.13 & 143.12 & \\
\hline $1-3$ & & 7.54 & & 49.2 & 16.5 & 82.44 & 150.71 & \\
\hline $2-1$ & \multirow[t]{3}{*}{0.5} & 7.46 & \multirow[t]{3}{*}{7.44} & 49.2 & 25.5 & 130.00 & 116.31 & \multirow[t]{3}{*}{120.42} \\
\hline $2-2$ & & 7.45 & & 49.2 & 26.0 & 128.92 & 108.82 & \\
\hline $2-3$ & & 7.40 & & 49.4 & 26.7 & 133.04 & 136.12 & \\
\hline $3-1$ & \multirow[t]{3}{*}{0.7} & 7.38 & \multirow[t]{3}{*}{7.34} & 49.6 & 35.1 & 176.68 & 87.14 & \multirow[t]{3}{*}{104.66} \\
\hline $3-2$ & & 7.33 & & 49.3 & 35.5 & 178.82 & 110.18 & \\
\hline $3-3$ & & 7.30 & & 49.3 & 34.8 & 174.50 & 116.66 & \\
\hline $4-1$ & \multirow[t]{3}{*}{0.8} & 7.37 & \multirow[t]{3}{*}{7.40} & 49.3 & 40.5 & 203.02 & 100.92 & \multirow[t]{3}{*}{100.11} \\
\hline $4-2$ & & 7.33 & & 49.1 & 39.7 & 194.85 & 83.20 & \\
\hline $4-3$ & & 7.49 & & 49.5 & 40.0 & 202.78 & 116.22 & \\
\hline $5-1$ & \multirow[t]{3}{*}{1.0} & 7.47 & \multirow[t]{3}{*}{7.34} & 49.2 & 49.7 & 251.20 & 88.95 & \multirow[t]{3}{*}{82.79} \\
\hline $5-2$ & & 7.33 & & 49.6 & 50.2 & 252.82 & 85.29 & \\
\hline $5-3$ & & 7.42 & & 49.3 & 50.4 & 253.76 & 74.12 & \\
\hline
\end{tabular}

As the length diameter ratio increases, the average strain rate tends to decrease linearly. When the aspect ratio is changed from 0.3 to 1 , the average strain rate decreases from $160.19 \mathrm{~s}^{-1}$ to $82.79 \mathrm{~s}^{-1}$ with a decrease of $48.318 \%$. At the same pressure and different specimen sizes, the strain rates calculated by SHPB test are different.

Table2. The data points selected in different group strain rate range

\begin{tabular}{|c|c|c|c|}
\hline Group number & $\beta$ & $\dot{\mathcal{\varepsilon}} / \mathrm{s}^{-1}$ & \multirow{2}{*}{$110-120$} \\
\hline \multirow{3}{*}{1} & 0.5 & 116.31 & \\
\cline { 2 - 3 } & 0.7 & 116.66 & \multirow{2}{*}{$100-110$} \\
\cline { 2 - 3 } & 0.8 & 116.22 & \multirow{2}{*}{$80-90$} \\
\cline { 2 - 3 } & 0.5 & 108.82 & \\
\cline { 2 - 3 } & 0.7 & 110.18 & 80.92 \\
\hline \multirow{3}{*}{3} & 0.8 & 87.14 & 83.20 \\
\hline
\end{tabular}


In order to eliminate the influence of strain rate effect, the initial data were rearranged and the experimental results under the same strain rate gradient were analyzed. The strain rate ranges were $110-120 \mathrm{~s}^{-1}, 100-110 \mathrm{~S}^{-1}$ and $80-90 \mathrm{~s}^{-1}$, respectively. Because the strain rates of specimens with different sizes under the same loading pressure are quite different, only data points can be selected from a limited range, and three data points can be selected from each set of strain rate ranges. The selected data points are shown in Table 2 .

According to the selection of data points in the strain rate range 110-120 $\mathrm{s}^{-1}, 100-110 \mathrm{~s}^{-1}$ and 80-90 $\mathrm{s}^{-1}$, the corresponding stress-strain curves are put into one group for analysis. Figure 5 shows the compressive stress-strain curves of 110-120 s-1, $100-110 \mathrm{~s}^{-1}$ and 80-90 s $\mathrm{s}^{-1}$ specimens with different aspect ratios.
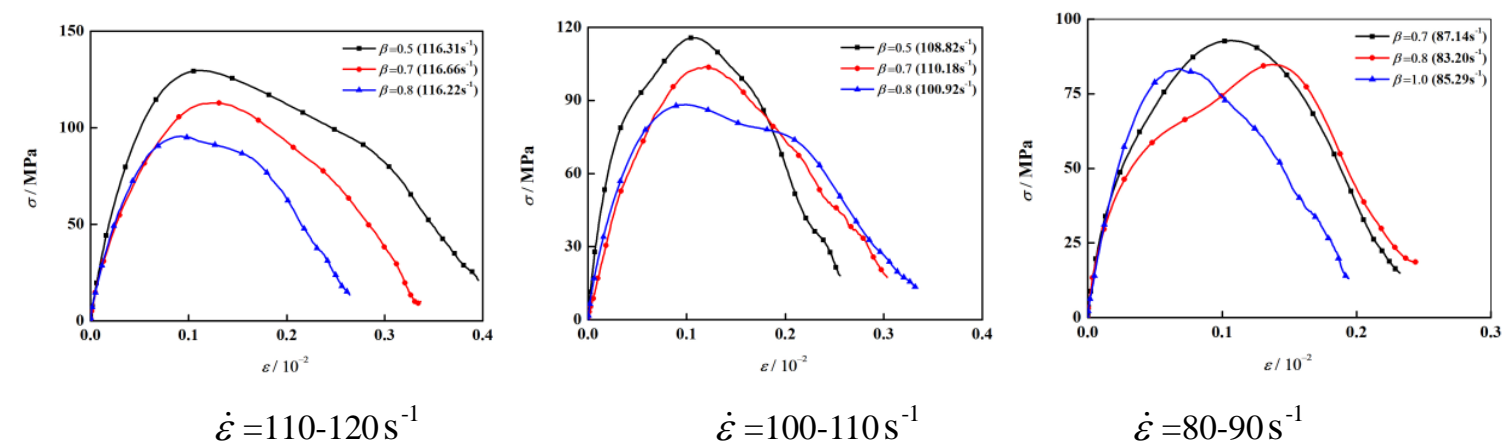

Figure5. The stress-strain curves of coal series sandstone under uniaxial compression test

By analyzing the stress-strain curves of the specimens with different aspect ratios under the same strain rate gradient, it can be seen that the dynamic peak stress of the specimens decreases gradually with the increase of the aspect ratios of the three groups of strain rates, and the slope of the elastic phase in the stress-strain curves also shows a decreasing trend.

\subsection{Variation of Elastic Modulus}

Table 3 shows the variation of mechanical properties of sandstone with aspect ratio under different strain rate groups. Figure 6 shows the variation curves of dynamic elastic modulus with aspect ratio in three strain rate ranges.

Table3. Dynamic modulus of elasticity changes with aspect ratio under different groups

\begin{tabular}{|c|c|c|c|c|c|}
\hline Strain rate range $/ \mathrm{s}^{-1}$ & $\beta$ & $\dot{\varepsilon} / \mathrm{s}^{-1}$ & $E_{\mathrm{d}} / \mathrm{Gpa}$ & $\sigma_{\mathrm{d}} / \mathrm{MPa}$ & $\varepsilon_{\mathrm{d}} / 10^{-2}$ \\
\hline \multirow{3}{*}{$110-120$} & 0.5 & 116.31 & 13.16 & 129.664 & 0.1130 \\
\cline { 2 - 6 } & 0.7 & 116.66 & 8.58 & 112.822 & 0.1310 \\
\cline { 2 - 6 } & 0.8 & 116.22 & 6.55 & 95.581 & 0.0921 \\
\hline \multirow{3}{*}{$100-110$} & 0.5 & 108.82 & 12.85 & 115.712 & 0.1070 \\
\cline { 2 - 6 } & 0.7 & 110.18 & 4.93 & 103.637 & 0.1225 \\
\cline { 2 - 6 } & 0.8 & 100.92 & 4.86 & 88.261 & 0.0990 \\
\hline \multirow{3}{*}{$80-90$} & 0.7 & 87.14 & 7.06 & 92.829 & 0.1067 \\
\cline { 2 - 6 } & 0.8 & 83.20 & 4.71 & 84.837 & 0.1373 \\
\cline { 2 - 6 } & 1.0 & 85.29 & 4.95 & 83.368 & 0.0885 \\
\hline
\end{tabular}

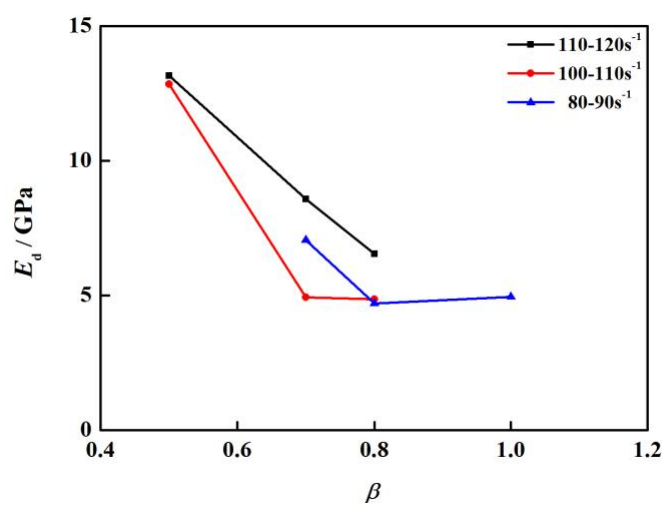

Figure6. The dynamic elastic modulus varies with the aspect ratio 
It can be seen from Figure 6 that the dynamic elastic modulus of coal measures sandstone decreases gradually with the increase of the ratio of length to diameter at the same strain rate level. Under higher strain rate, the dynamic elastic modulus decreases quick with the increase of aspect ratio. The dynamic modulus of elasticity decreased from $13.16 \mathrm{GPa}$ to $6.55 \mathrm{GPa}$ and $12.85 \mathrm{GPa}$ to $4.86 \mathrm{GPa}$ with the increase of aspect ratio from 0.5 to 0.8 at strain rates of $110-120 \mathrm{~s}^{-1}$ and $100-110 \mathrm{~s}^{-1}$, respectively, with the decreases of $50.23 \%$ and $62.18 \%$. When the strain rate is in the range of $80-90 \mathrm{~s}^{-}$ ${ }^{1}$, the dynamic elastic modulus decreases from 7.06GPa to $4.95 \mathrm{GPa}$ with the increase of aspect ratio from 0.7 to 1.0 , and the decrease is $29.89 \%$. Because each group of strain rates are selected within a certain range of values, it cannot be fully guaranteed that under the same strain rate, the analysis results will have a certain error. On the whole, it can be concluded that the dynamic elastic modulus of sandstone decreases gradually with the increase of the ratio of length to diameter at the same strain rate, i.e. the deformation resistance decreases gradually; the dynamic elastic modulus decreases more with the increase of the ratio of length to diameter at high strain rate than at low strain rate. It can be inferred that the sensitivity of the dynamic elastic modulus to the aspect ratio of the specimen at high strain rate is greater than that at low strain rate.

\subsection{Variation Law of Peak Stress}

Figure 7 gives the variation curves of the dynamic peak stress with the aspect ratio in three strain rates.

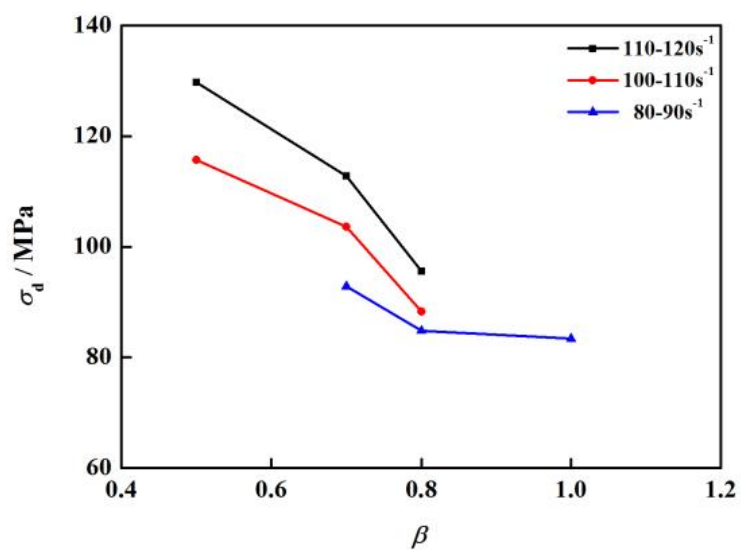

Figure7. The curves of dynamic peak stress with aspect ratio

It can be seen from Figure 7 that the dynamic peak stress of coal measures sandstone decreases gradually with the increase of the ratio of length to diameter at the same strain rate level. Under higher strain rate, the dynamic peak stress decreases quick with the increase of aspect ratio. The dynamic peak stress decreased from 129.664 MPa to $95.581 \mathrm{MPa}$ and $115.712 \mathrm{MPa}$ to $88.261 \mathrm{MPa}$ with the increase of the aspect ratio from 0.5 to 0.8 in the range of $110-120 \mathrm{~s}^{-1}$ and $100-110 \mathrm{~s}^{-1}$, respectively, with the decrease of $26.29 \%$ and $23.72 \%$. The dynamic peak stress decreases from $92.829 \mathrm{MPa}$ to 83.368 MPa with the increase of aspect ratio from 0.7 to 1.0 in the strain rate range of 80-90 s-1, with a decrease of only $10.19 \%$. The variation amplitude is small at relatively high strain rate. Similar to the dynamic modulus of elasticity data, each group of strain rate statistics are within a certain range of values, it cannot fully guarantee that under the same strain rate, the analysis results will have certain errors. But on the whole, with the increase of the ratio of length to diameter under the same strain rate, the dynamic peak stress of coal measures sandstone gradually decreases. The dynamic peak stress of coal measures sandstones can be regarded as the dynamic compressive strength of coal measures sandstones. It can be inferred that the dynamic compressive strength of coal measures sandstones decreases gradually with the increase of length-diameter ratio at the same strain rate, At high strain rates, the sensitivity of dynamic compressive strength to specimen aspect ratio is larger than that of low strain rate.

\subsection{Variation of Peak Strain}

Dynamic peak strain is also one of the parameters to characterize the ultimate deformation capacity of rock. Figure 8 shows the variation curves of dynamic peak strain with aspect ratio in three strain rate ranges. 


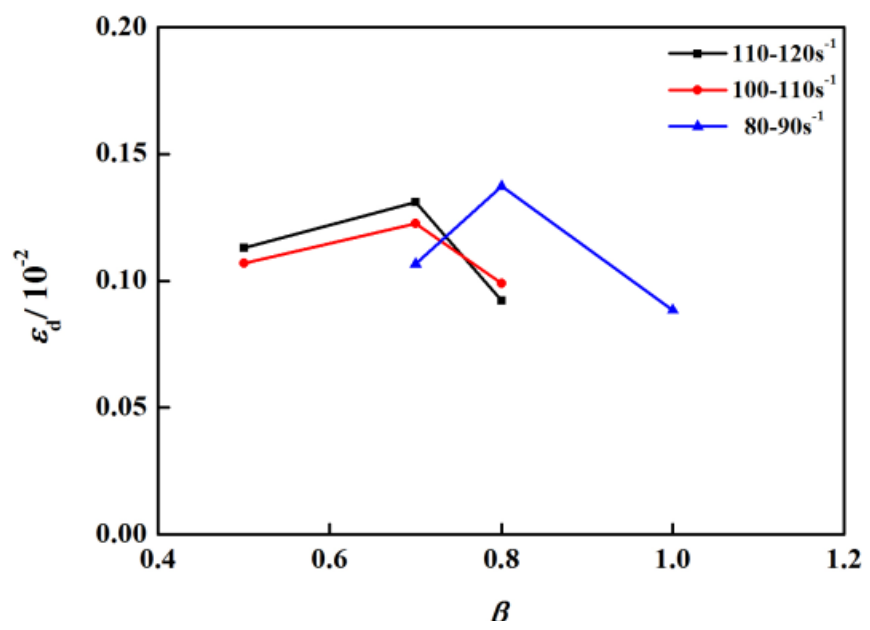

Figure8. The curves of dynamic peak stress with aspect ratio

It can be seen from Figure 8 that the dynamic peak strain of coal measures sandstones is nonlinear with the increase of the ratio of length to diameter at the same strain rate level, and then increases and decreases at first. Similarly, because the strain rate statistics of each group are within a certain range of values, it cannot be fully guaranteed that under the same strain rate, there is a certain error in the analysis results. The dynamic peak strain of the length-diameter ratio of each specimen of coal measures sandstone is generally in the range of 0.0010-0.0013, and the variation amplitude has little influence on the relative strain rate. It can be concluded that the dynamic peak strain of coal bearing sandstone is less affected by size effect.

\section{CONCLUSION}

In this paper, the size effect of coal measures sandstone is studied. By changing the ratio of length to diameter in SHPB test under fixed loading pressure, the change rule of mechanical properties of coal measures sandstone with specimen size is analyzed, and the change of failure characteristics with specimen size is studied. The conclusions of this paper are as follows:

- The data points under the same strain rate were selected when the variation of mechanical properties of coal measures sandstone with the ratio of length to diameter was studied. The effect of strain rate effect on test results is eliminated, and the ratio of length to diameter is ensured as a single variable. The strain rate ranges are 110-120 $\mathrm{s}^{-1}, 100-110 \mathrm{~s}^{-1}$ and $80-90 \mathrm{~s}^{-1}$, respectively. With the increase of the ratio of length to diameter, the slope and peak stress of the elastic stage in the stress-strain curve decrease gradually.

- At the same strain rate, the dynamic elastic modulus of coal measures sandstone decreases gradually with the increase of length-diameter ratio, that is, the anti-deformation ability weakens gradually. The maximum bearing capacity of coal measures sandstone gradually decreases, and the sensitivity of dynamic compressive strength to the ratio of length to diameter under high strain rate is greater than that under low strain rate.

\section{REFERENCES}

[1] Griffith, A.A. The Phenomena of Rupture and Flow in Solids [M].London: Philosphical Transactions of the Royal Society of London, 1921.

[2] Hudson J A, Crouch S.Soft, Stiff and serve-controlled testing machines [J].Eng.Geol, 1972, 6(3):155-189.

[3] Bazant Z P, Chen E P.Scaling of structural failure [J].Applied Mechanics Reviews, 1997, 50(10):593-627.

[4] J C Jaeger, N G W Cook. Foundation of rock mechanics [M]. Beijing: Science Press, 1981.

[5] Obert L, Windes S L, Duvall W I. Standardized test for determining the physical properties of mine rock [M].U.S.Bur.Mines Rept. Invest, 1946.

[6] Su Chengdong. Experimental study on the effect of marble particle size and specimen size on impact tendency [J].Acta Sinica Sinica of Rock Mechanics and Engineering, 2004, (22): 3750-3753. 
[7] Du Jing. Rock dynamic characteristics under different aspect ratio [D]. Changsha: Central South University, 2011.

[8] Yin Xiaotao, Ge Xiu-run, Li Chun-guang, et al. Study on Optimum Length-Diameter Ratio of Rock Specimens Based on Numerical Experiments [J]. Journal of Rock Mechanics and Engineering, 2010 (S2): 3608-3615.

Citation: Guo Shiru et.al, (2018). Size Effect of Mechanical Properties of Coal Measures Sandstone under High Strain Rate, International Journal of Mining Science (IJMS), 4(2), pp.23-30, DOI: http://dx.doi.org/ 10.20431/2454-9460.0402003

Copyright: (C) 2018 Authors. This is an open-access article distributed under the terms of the Creative Commons Attribution License, which permits unrestricted use, distribution, and reproduction in any medium, provided the original author and source are credited 